\title{
Warum Sie sich auch im Jahr 2009 über die SÄZ ärgern werden - aber hoffentlich nicht nur
}

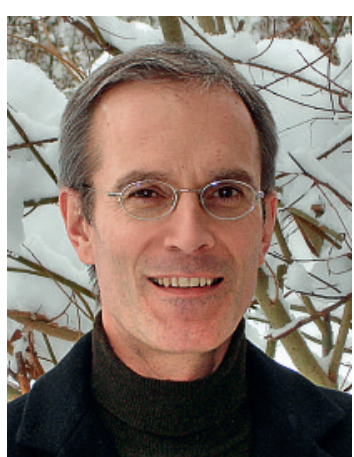

Bruno Kesseli

Als «Randfiguren der holzverarbeitenden Industrie» soll Willy Brandt die Journalisten einmal bezeichnet haben. Eine zwar wenig schmeichelhafte, aber unbestreitbar witzige Retourkutsche an die schreibende Zunft, die den ehemaligen deutschen Bundeskanzler ihrerseits nicht immer mit Samthandschuhen anfasste. Nachdem die Schweizerische Ärztezeitung nach wie vor auf einem holzhaltigen Papier mit einer leicht gestrichenen Oberfläche gedruckt wird, fällt die SÄZRedaktion grundsätzlich ebenfalls in den Gültigkeitsbereich der Brandt'schen Definition.

Dennoch ist «bei uns» einiges anders als bei den Printmedien, die Willy Brandt wohl vor seinem geistigen Auge hatte, als er obigen Ausspruch tat. Und nachdem die Zeit um den Jahreswechsel traditionellerweise für Rück- und Ausblicke sowie Reflexionen und Analysen aller Art genutzt wird, sei es erlaubt, an dieser Stelle wieder einmal einige grundsätzliche Betrachtungen zur SÄZ und zu ihren Charakteristika anzustellen

Da wäre zunächst der Umstand erwähnenswert, dass die SÄZ eine Einreichungszeitschrift ist, die - von wenigen Ausnahmen abgesehen - nicht von Journalisten gemacht wird, sondern zu einem sehr grossen Teil von ihren Leserinnen und

\section{«Die SÄZ wird als offene Plattform der Ärzteschaft auch in Zukunft für anregende, unterhaltsame und inspirierende Leseerlebnisse sorgen»}

1 Leo Longanesi (1905-1957), italienischer Journalist, Verleger, Zeichner, Illustrator und Humorist.
Lesern. Dies bringt den Vorteil, dass der zweite Teil des folgenden, Leo Longanesi [1] zugeschriebenen Zitats auf SÄZ-Autoren in der Regel nicht zutrifft: «Ein Journalist ist jemand, der andern einleuchtend Dinge erklärt, die er selber nicht versteht.» Oder wie es der Publizist und Satiriker Karl Kraus in seiner unnachahmlichen Art zuspitzte: «Keinen Gedanken haben und ihn ausdrücken können - das macht den Journalisten.»

An potentiellen Beiträgen herrscht bei der SÄZ kein Mangel, ganz im Gegenteil. Man könnte sich vorstellen, dass die Redaktion diese komfortable Ausgangslage dazu nutzt, die Beine hochzulagern und die Zeitschrift mehr oder weniger nach dem Zufallsprinzip aus dem prallgefüllten Einreichungstopf zu speisen. Das Gegenteil kommt der Realität näher. Abgesehen davon, dass es bezüglich des ersten Teils der beiden letztgenannten
Zitate, also in Bezug auf die journalistischen Qualitäten, bei den eingereichten Manuskripten mitunter etwas hapert, ist gerade deren Quantität und Heterogenität eine enorme Herausforderung für die Redaktion. Als Leserin oder Leser können Sie versichert sein, dass wir den Anspruch der SÄZ sehr ernst nehmen, die Vielfalt der Schweizer Ärzteschaft möglichst massstabsgetreu abzubilden. Die vor einem Jahr vorgenommene Erweiterung der Redaktion bietet Gewähr dafür, dass Publikationsentscheide aufgrund eines breiten Konsenses zustande kommen, und ich möchte meinen Redaktionskolleginnen und -kollegen an dieser Stelle herzlich für ihre engagierte Arbeit danken.

Grund, sich über die SÄZ zu ärgern, wird es aber allen Bemühungen der Redaktion zum Trotz auch in Zukunft reichlich geben. So mussten wir aufgrund des härter gewordenen wirtschaftlichen Umfeldes die Anzahl redaktioneller Seiten pro Ausgabe deutlich verringern, um bei den Produktionskosten zu sparen. Dies hat beispielsweise zur Folge, dass wir von den Autoren mehr Disziplin bezüglich Einhaltung der Längenvorgaben fordern müssen, dass die Wartezeit bis zum Erscheinen der Artikel länger geworden ist und dass sich unsere Ablehnungsquote leicht erhöht hat - sie bleibt indes im Vergleich zu Fachjournalen sehr tief.

Natürlich gibt es auch Fehlleistungen der Redaktion, doch im Grunde genommen ist «Ärger über die $S \ddot{A} Z$ » schon in ihrem Konzept angelegt: Man nervt sich über wirtschaftliche Ungerechtigkeiten, arrogante Behörden, dogmatische oder schwärmerische Kollegen, institutionelle Leerläufe oder «unfähige» Standespolitiker. Solange die ganze Buntheit der gesundheitspolitischen Landschaft sich in der SÄZ widerspiegeln darf und soll, wird die wöchentliche Lektüre häufig mit einer Prise Ärger gewürzt sein.

Dies ist auch nicht weiter tragisch, denn, so dürfen wir optimistisch hoffen, die SÄZ wird als offene Plattform der Ärzteschaft auch in Zukunft für anregende, unterhaltsame und inspirierende Leseerlebnisse sorgen. Dass wir auch - und vor allem - diese Funktion erfüllen (dürfen), belegen zahlreiche Leserechos, die uns motivieren, auch inskünftig die Quadratur des Kreises anzustreben, nämlich eine Zeitschrift zu machen, die allen Ärztinnen und Ärzten in der Schweiz etwas bietet.

In diesem Sinne wünsche ich Ihnen im Namen der Redaktion ein glückliches neues Jahr.

Bruno Kesseli, Chefredaktor 